\title{
The Potential Role of Nitric Oxide in Halting Cancer Progression Through Chemoprevention
}

\author{
Huzefa Vahora', Munawwar Ali Khan ${ }^{2}$, Usama Alalami ${ }^{2}$, Arif Hussain ${ }^{1}$ \\ 'School of Life Sciences, Manipal University, ${ }^{2}$ Department of Natural Science and Public Health, College of Sustainability Sciences and Humanities, \\ Zayed University, Dubai, United Arab Emirates
}

\begin{abstract}
Nitric oxide (NO) in general plays a beneficial physiological role as a vasorelaxant and the role of NO is decided by its concentration present in physiological environments. NO either facilitates cancer-promoting characters or act as an anti-cancer agent. The dilemma in this regard still remains unanswered. This review summarizes the recent information on NO and its role in carcinogenesis and tumor progression, as well as dietary chemopreventive agents which have NO-modulating properties with safe cytotoxic profile. Understanding the molecular mechanisms and cross-talk modulating NO effect by these chemopreventive agents can allow us to develop better therapeutic strategies for cancer treatment.
\end{abstract}

(J Cancer Prev 2016;21:1-12)

Key Words: Chemoprevention, Nitric oxide, Inducible nitric oxide synthase, Endothelial nitric oxide synthase, Neoplasms

\section{INTRODUCTION}

Nitric oxide (NO) is a multifunctional gaseous transmitter which is lipophilic, as well as one of the smallest molecules found in nature ${ }^{1-3} \mathrm{~A}$ free radical in gaseous state functions as a messenger via cyclic GMP (cGMP). ${ }^{1}$ It was identified as a vasoactive small molecule in the 1980s and its cardiovascular activities are significant in relation to its vasorelaxation function as well as anti-thrombotic and anti-inflammatory effects. As a gasotransmitter, it regulates many physiological functions in the body, including neurotransmission, immune response, and anti-pathogenic effect, ${ }^{1-3}$ although NO is quite unstable and possess a half-life of 1 to 5 seconds in vivo.

Under normal physiological conditions, NO is produced by three isoforms of nitric oxide synthase (NOS) (Fig. 1), Neuronal NOS (nNOS/NOS1) and endothelial NOS (eNOS/NOS3) form the constitutive NOS category (cNOS), activating NO production for seconds to minutes in nanomolar concentrations. Contrastingly, the third isoform, inducible NOS (iNOS/NOS2), produces greater amounts of NO, reaching micromolar concentrations and lasting hours or days. CNOS members are dependent on the calcium ion concentrations for their activity, thus they are able to produce lower amounts of $\mathrm{NO}$ for shorter durations, in comparison to iNOS which is independent of the calcium ion concentration. ${ }^{1.3}$ NOS enzymes are dimeric in nature and two distinct catalytic domains, N-terminal oxygenase domain, and C-terminal reductase domain, are present on each monomer. The substrates binding to the N-terminal are Heme-5,6,7,8- tetrahydrobiopterin (BH4), L-arginine, and oxygen and the substrates binding to the C-terminal are NADPH, flavin mononucleotide, and flavin adenine dinucleotide. ${ }^{1} \mathrm{NO}$ production is catalyzed by NADPH and oxygen as cosubstrates of L-arginine in the presence of NOS. The process of NO synthesis takes place in two steps: (i) hydroxylation of L-arginine to N $\omega$-hydroxy-L-arginine by NOS and (ii) oxidation of N $\omega$-hydroxy-L-arginine to L-citrulline and NO. The unpaired electrons of NO impart its reactivity towards

Received February 11, 2016, Revised March 10, 2016, Accepted March 14, 2016

Correspondence to: Arif Hussain

School of Life Sciences, Manipal University, P.O. Box 345050, Dubai, United Arab Emirates

Tel: +971-44290738, Fax: +971-4369-4541, E-mail: dr.arifhussain@yahoo.co.in, ORCID: Arif Hussain, http://orcid.org/0000-0002-0851-4845

Copyright (C) 2016 Korean Society of Cancer Prevention

(c) This is an Open Access article distributed under the terms of the Creative Commons Attribution Non-Commercial License (http://creativecommons.org/licenses/by-nc/4.0) which permits unrestricted non-commercial use, distribution, and reproduction in any medium, provided the original work is properly cited. 
inorganic molecules (oxygen, superoxide, or transition metals), DNA structures, and prosthetic groups, thus portraying its extensive biological activity. ${ }^{3}$

The actions of NO are mainly mediated through cGMPdependent manner as well as cGMP-independent manner. The heme component of soluble guanylyl cyclase is targeted by NO, which further undergoes coupling with c-GMP-dependent protein kinase $\mathrm{G}$ and phosphodiesterases as well as cyclic nucleotide gated channels. In circumstances where cGMP is not available, the actions of NO are carried out independent of cGMP at low concentrations mainly in three ways, (i) interaction with proteins containing transition metal, (ii) interaction with proteins without the attached NO group, and (iii) modulation of cell signaling by posttranslational modification, mainly by forming S-nitrosothiol (SNO), which is achieved by coupling of a nitroso species to a reactive thiol group in specific cysteine residues, namely, S-nitrosylation. ${ }^{1-3}$

Over many years, NO was considered to be oncogenic in nature. Evidence has shown that NO plays a variety of roles in

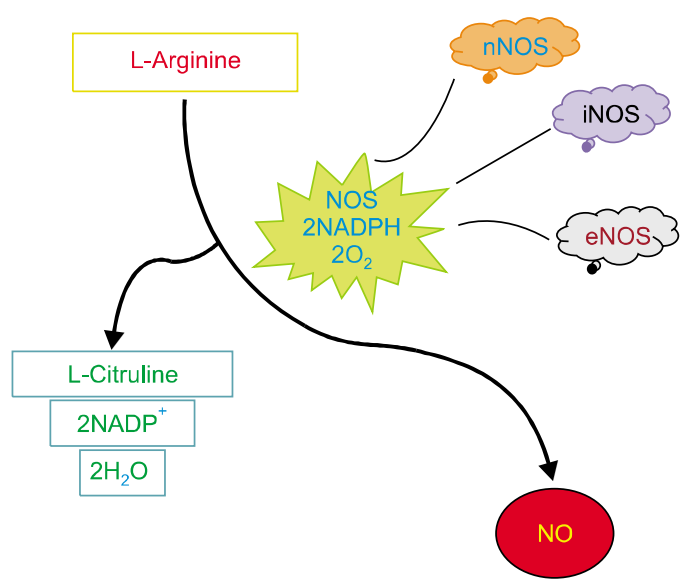

Figure 1. The pathway elucidating the production of nitric oxide (NO). NOS, NO synthase; $\mathrm{NADP}^{+}$, nicotinamide adenine dinucleotide phosphate; nNOS, neuronal NOS; iNOS, inducible NOS; eNOS, endothelial NOS. various stages of carcinogenesis by damaging the DNA, activating oncogenes, regulating apoptosis and metastasis, and inhibiting enzymes for DNA repair and tumor suppressor genes. Pro-tumor effects of NO were linked to the expression of NO-producing enzymes in tumor progression. ${ }^{2} \mathrm{NO}$ also portrays anti-tumor effects by utilizing the immune defense mechanisms in animal models of various human cancers. ${ }^{1.3}$

Since decades, a dual role of NO has been observed and more studies is conducted to unravel the mysterious functions of this versatile molecule. Therefore, this review aims at showing the recent information on $\mathrm{NO}$ and its role in carcinogenesis and tumor progression.

\section{ROLE OF NITRIC OXIDE IN CANCER BIOLOGY}

NO, a free radical and water-soluble gas produced endogenously, regulates quite a few essential biological processes. ${ }^{4}$ Since a few decades, an interest in NO has been increased as a molecule involved in carcinogenesis and tumor progression. However, a controversial facet exists in understanding its role in the biology of cancer. ${ }^{4}$ This small molecule possesses the quality to either induce cancer progression or halt cancer growth and act as therapeutic agents. ${ }^{4.5}$ In conditions where NO is at lower concentrations, it aids in angiogenesis, which stimulates tumor progression by giving blood flow access to the tumor and subsequently result in cell proliferation (Fig. 2). ${ }^{5}$ On the contrary, higher levels of NO tend to be cytotoxic to cancer cells. This is achieved by the formation of peroxynitrite, which acts as an inducer of apoptosis and other toxic species during immune surveillances. ${ }^{5}$ Interestingly, peroxynitrite plays a dual role by aiding in inflammation-related carcinogenesis through the formation of 8-nitroguanine, a DNA-damaging entity and biomarkers. ${ }^{3-7}$

The release of various growth factors and mediators, such as interleukin (IL)-6, IL-8, TNF- $\alpha$, and NO, during the subsequent

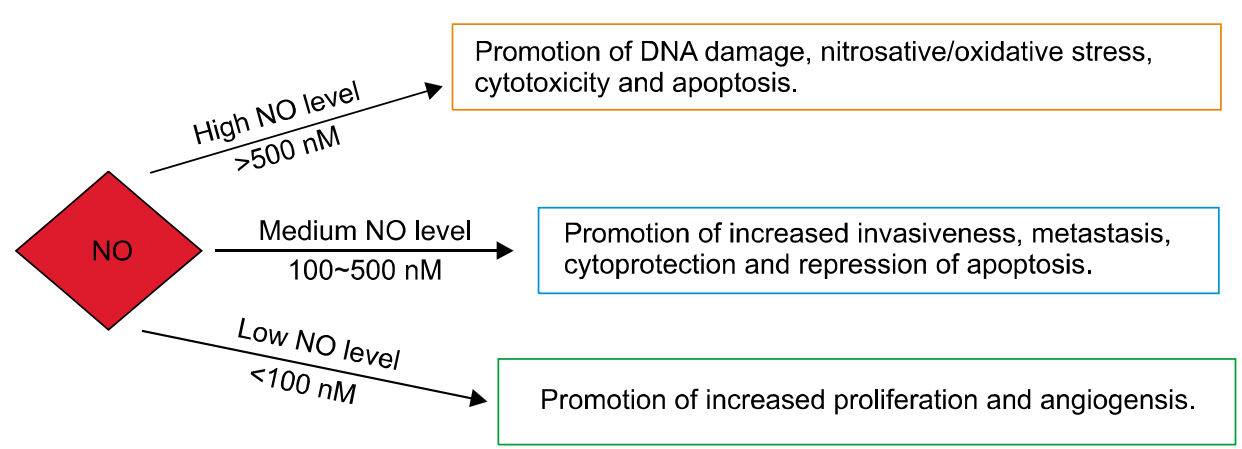

Figure 2. Concentration-based functions of nitric oxide (NO). 
stages of tumorigenesis, changes the host microenvironment, inducing inflammation and preventing apoptosis. ${ }^{3}$ The calcium-independent NOS2 (iNOS) activation in almost all nucleated mammalian cells produces NO in higher concentrations for longer durations in comparison to its other two isoforms. The regulation of NOS2 lies in the hands of the tumor suppressor gene $\mathrm{p} 53$, which inhibits NOS2 by operating a negative feedback mechanism against high levels of NOS2. This relation has shown some significant implications pertaining to cancer and its progression (Fig. 2). ${ }^{4}$ The cells transfected with iNOS showed a substantial decrease in growth under in vitro conditions, which was indicative of cytostatic nature of NO. This effect was observed to be tumor-specific under in vivo conditions. Some tumors showed less aggressive phenotypes and others displayed a very aggressive nature. ${ }^{8}$

The upregulation of iNOS plays the most compelling role in the elevation and inhibition of tumorigenesis and metastasis. Suppression of tumorigenesis by upregulation of iNOS was evident in oral cancer cells. ${ }^{9}$ Poor patient survival is often related to expression of iNOS in malignant melanoma stage III patients, whereas this is observed to a lesser extent in patients with breast cancer. Stage III ovarian cancer patients responded better towards first line chemotherapy when iNOS was not expressed. ${ }^{10}$ This dichotomous nature of NO implies that its level in cancers varies quite significantly in relation to iNOS expression.

\section{EFFECTS OF NITRIC OXIDE ON MAJOR CANCER HALLMARKS}

\section{Inflammation}

It is estimated by The International Agency for Research on Cancer that infectious disease-induced cancer cases around the world account for approximately 18\%, whereas chronic inflammation-induced cancer cases account for approximately $25 \%{ }^{6}$

Some of the important factors for carcinogenesis which have been noted are infection and chronic inflammation. Inflammatory environment results in the production of reactive nitrogen species (RNS) and reactive oxygen species (ROS) from epithelial and inflammatory cells, which consequently lead to oxidative and nitrative damage of the DNA, such as 8-oxo-7,8-dihydro-2-deoxyguanosine (8-oxo-dG) and 8-nitroguanine. These DNA damage cause mutations in stem cells and subsequent initiation/progression. iNOS is upregulated by transcription factors such as hypoxia-inducible factor $1-\alpha$, STAT, NF- $\mathrm{KB}$, and TNF- $\alpha$. NF- $\kappa B$, plays a very crucial role for inducing iNOS, which subsequently functions to be a tumor promoter during inflammation-related carcinogenesis (Fig. 3). ${ }^{9}$

\section{Metastasis}

Colonization of tumors in other sites of the body takes place in multistep process, including local invasion, entry in the circulation, transport to distant sites, exit from circulation, and ultimately colony formation. Though these events appear to be synonymous in most of the tumors, there appears to be some tissue specific characteristics which prevail in the molecular or phenotypic areas. One important characteristic is the colonization of a specific tumor to a specific location in the body. For example, prostate cancer mainly metastasizes to the bone whereas ocular melanoma establishes colonies in the liver. Interestingly, breast cancer shows metastasis to range of tissues such as bone, brain, liver, and lungs.

It is a well-established fact that NO plays an important role in the process of angiogenesis/lymphangiogenesis. Not only is the formation of these vessels undertaken by NO but its maintenance is also looked upon by it. Thus, the expression of NOS can be correlated to lymphatic metastasis. In particular, eNOS is the mediator for VEGF-C induced lymphangiogenesis and is thus involved in lymphatic metastasis. It has been demonstrated that inhibiting eNOS pharmacologically or genetically decreases the number of tumor cells reaching to the draining lymph node of that tumor and thus reduces the chances of macroscopic metastasis formation. This suggests that NO participates in the early steps of lymphatic metastasis. ${ }^{11}$ Another important factor

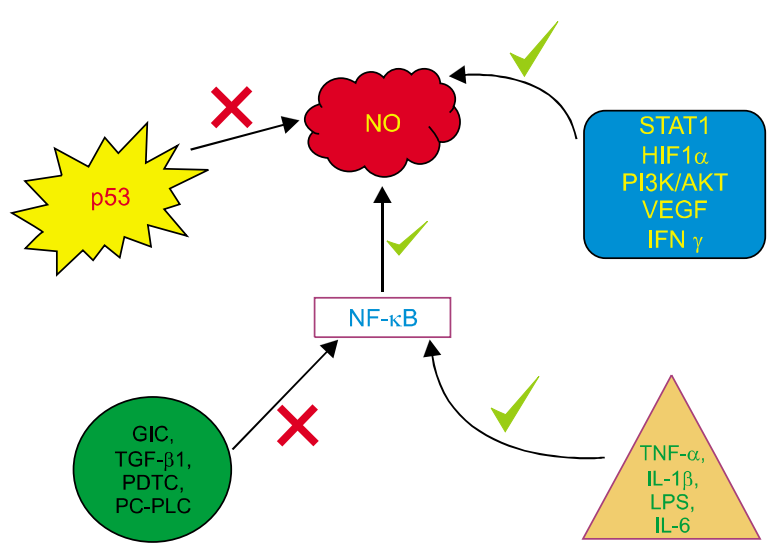

Figure 3. NF- $\mathrm{KB}$ plays a crucial role in the production of nitric oxide (NO) by upregulation of nitric oxide synthase genes, which subsequently results in inflammation. HIF $1 \alpha$, inducible factor 1- $\alpha$; GIC, gap junctional intercellular communication; PDTC, pyrrolidine dithiocarbamate; PC-PLC, phosphatidylcholine-specific phospholipase; IL, interleukin; LPS, lipopolysaccharide. 
for achieving metastasis is the epithelial mesenchymal transition (EMT). In the earlier stages of cancer, the tumor is encapsulated and localized by the basement membrane. As the cancer progresses, the epithelial cells are transformed to act as mesenchymal cells, losing their epithelial properties. Once these transformed cells enter the circulation and reach new sites, they undergo mesenchymal epithelial transition and then establish new tumors. ${ }^{1}$ One of the main features of such a transformation is the anomalous expression of cell adhesion molecules that is mediated by NO, the paucity of which triggers the dissemination of tumor cells. Of these, E-cadherin is associated with the early stages of EMT. ${ }^{12}$ It was demonstrated that the downregulation of E-cadherin is a potent prognostic factor in determining the metastasis of gastric cancer. ${ }^{13}$

Other endocrine markers, such as estrogen-related receptor alpha, also suppressed E-cadherin expression, thereby inducing EMT in lung carcinoma. ${ }^{14}$ TGF- $\beta$ induced modulation of E-cadherin aggravated ovarian cancer metastasis. ${ }^{15}$ Induction of NO synthesis resulted in an upregulation in E-cadherin expression. ${ }^{16}$ ATP receptor $\mathrm{P} 2 \mathrm{X} 7$, another stimulus that is higher in the extracellular microenvironment of cancer cells than normal cells, has been recently concluded to promote tumor invasion and hence be involved in metastasis. ${ }^{12} \mathrm{NO}$ also impairs the regulation of matrix metalloproteinase (MMP), which is crucial to controlling matrix remodeling and metastasis. ${ }^{17,18}$

\section{Apoptosis}

NO has been shown to induce apoptosis through posttranslational modifications. ${ }^{19}$ Studies on cervical cancer HeLa cells, suggest the role of NO donor in increasing Fas expression, which in turn induces apoptosis. Conversely, enormous data on the anti-apoptotic effect of NO has been well accumulated. NO augmented DNA damage in lung adenocarcinoma which in fact triggered the anti-apoptotic machinery. ${ }^{20}$ The predominant reason for the inhibition of apoptosis by $\mathrm{NO}$ is the occlusion of caspase 3 expression. ${ }^{21}$ S-nitrosylation of the active cysteine rich sites of caspases, results in oxidation of thiols (involved in cell survival and apoptotic signaling pathway), thereby inhibiting the mechanism of apoptosis. ${ }^{21,22}$ Denitrosylation of caspase 3 in cancer cells by adenovirus ZD55-IL-24 has clearly demonstrated the crucial role of caspase 3 pathway in causing apoptosis. ${ }^{21}$ It was also substantiated in ovarian cancer. ${ }^{21}$

Upregulation of $\mathrm{BCl} 2$ plays a significant role in inhibiting cell death. ${ }^{22}$ Additionally, several NO donors have shown to activate anti-apoptotic pathways such as NF- $\kappa B$ (Fig. 3) ${ }^{22} \mathrm{NO}$ also activates Ras protein, which in turn augments the anti-apoptotic Akt pathway. ${ }^{23}$ A recent study on lung cancer revealed that prolonged NO exposure intriguingly led to chemotherapeutic resistance to cisplatin, through the upregulation of anti-apoptotic genes $\mathrm{BCl} 2$ protein kinase $\mathrm{AKT}^{22,23} \mathrm{~A}$ calcium binding protein, regucalcin, interferes with the calcium signalling and hence influences the gene expression of calcium dependent NOS, as observed in hepatoma cells. This suppressed apoptosis, as manifested by the over-activation of $\mathrm{BCl} 2$ and inactivation of caspases. ${ }^{24}$ Consequently, NO inhibitors were analysed for their therapeutic potential in order to promote apoptosis in nasopharyngeal cancer. ${ }^{25} \mathrm{NO}$ inhibitors rendered a reactivation of apoptosis and angiogenesis in adenoid cystic carcinoma. ${ }^{26}$ It is known that NO interferes with the DNA binding activity of many zinc finger transcription factors through S-nitrosylation of cysteine thiol groups and formation of SNO subsequently. Oxidation of these thiol proteins may act as switches in signaling pathways. NO is also thought to modulate many other thiol-containing enzymes and regulatory proteins, such as NF- $\mathrm{kB}{ }^{22}$

\section{Angiogenesis}

Angiogenesis is a critical molecular event involved in tumor progression. ${ }^{27} \mathrm{~A}$ wide array of genes and transcription factors act as pro-angiogenic mediators, including $\mathrm{NO}$, all of which are involved in promoting neovascularization. ${ }^{27}$ Several studies have implicated the role of $\mathrm{NO}$ in angiogenesis. ${ }^{27} \mathrm{NO}$ stimulates epidermal growth factor receptor (EGFR) signalling pathway, as well as the tumor suppressor p53 and VEGF, which are collective mediators that exacerbate angiogenesis. ${ }^{28}$ NO-mediated angiogenesis is linked to an anomaly in the regulation of angiogenesis inhibitor thrombospondin $2 .^{27,28}$

Proliferative and angiogenic growth factors such as VEGF have predominantly shown to affect NO signaling and hence augment angiogenesis. ${ }^{29}$ VEGF expression was shown to induce NOS2 in various human cancers. ${ }^{30,31}$ VEGF stimulates eNOS expression, which has been identified as a downstream regulator of angiogenesis, ${ }^{31,32}$ by the activation of receptor tyrosine kinase and protein kinase $\mathrm{C}$ signalling pathway. ${ }^{32}$ The relation between NO and VEGF is reciprocal. Studies on hypoxia-induced iNOS elevation possibly through NF- $\mathrm{KB},{ }^{33}$ have also shown a paramount elevation in the expression of VEGF during endometrial angiogenesis. $^{34}$

The epidermal growth factor (EGF) is yet another ligand binding to protein associated with tumor progression, owing to its angiogenic potential. ${ }^{35}$ Previous studies have conclusively shown EGF to be a coactivator in iNOS transcription. ${ }^{36}$ Previously, an aberrant expression of EGFR in squamous cell carcinoma 
elevated the expression of iNOS. ${ }^{36}$ A study has further substantiated the involvement of iNOS in EGFR up regulation in gall bladder tumorigenesis. ${ }^{35}$ Another study showed upregulation of eNOS through EGF like domain of $\mathrm{CD} 93$ protein in endothelial cells. ${ }^{37}$ The data from previous study is associated with the stimulation of NO production through EGFR via the PI3K-dependent pathway. ${ }^{35.37}$

NO upregulation is also associated with the increase in the expression of COX-2, inhibition of which abates the process of tumor angiogenesis in different cancer. ${ }^{38.39}$ Another protein, angiopoietin-like 4 (ANGPTL4), has recently shown to upregulate iNOS expression. ANGPTL4 is associated with regulating vascular permeability and is therefore crucial in promoting angiogenesis. ${ }^{40}$ It was explicitly demonstrated that inducible NOS upregulated through the application of ANGPTL4 recombinant protein in a mouse model. The study showed the involvement of integrin/JAK/STAT3 pathway in the increase of ANGPTL4-mediated iNOS elevation. ${ }^{41}$

Hence, NO has been substantiated to exert its angiogenic property via the modulation of various genes and transcriptional factors that exacerbate angiogenesis. ${ }^{42}$

\section{NITRIC OXIDE IN VARIOUS CANCERS}

\section{Endometrial cancer}

Increased NO levels are manifested in the progression of endometrial carcinogenesis. ${ }^{43}$ Previous reports indicate the interaction between iNOS, Bcl-2, and $\mathrm{p} 53$ to be a prognostic factor associated with the progression of endometrial carcinoma. ${ }^{43}$ Molecular studies have shown that the susceptibility to gynecological cancers such as endometrial and cervical cancers increases by inflammatory markers including NOS and COX-2. ${ }^{44}$ There is a positive correlation between elevated iNOS, COX-2, and angiogenesis in endometrial tumors. ${ }^{43.44}$ A recent case study on the Turkish women identified the G894T and variable number tandem repeat (VNTR) intron 4 polymorphisms in the eNOS gene to instigate endometrial cancer in such women. ${ }^{45}$ eNOS expression has also been correlated with endometrial invasion. ${ }^{45}$ Various therapeutic agents administered for endometrial cancer emphasize on their anti-inflammatory potential, especially with respect to the downregulation of NOS expression. ${ }^{43.44}$

\section{Prostate cancer}

There has been strident investigation to associate the risk of prostate cancer with NO synthase levels. ${ }^{45}$ A plethora of meta-analyses has identified NOS3 gene polymorphisms as strong susceptibility factors for the progression towards prostate cancer. ${ }^{46} \mathrm{~A}$ meta-analysis conducted by Zhao et al. ${ }^{47}$ suggested the eNOS gene 894G $>$ T polymorphism to aggravate the onset of prostate cancer in males. Nikolić et al. ${ }^{48}$ also corroborated the involvement of eNOS or NOS3 gene in the pathogenesis of prostate cancer. NOS3 rs1799983 polymorphism augmented the risk of prostate cancer in various populations. ${ }^{49}$ As one of the possible mechanisms, the involvement of the NO receptor component, sGC $\alpha 1$, in mediating the proliferation of prostate carcinogenesis, has been surmised. ${ }^{49}$ Anti-cancer agents such as gold lotion have successfully demonstrated their anti-carcinogenic potential through the downregulation of iNOS..$^{50.51} \mathrm{Yu}$ et $\mathrm{al}^{52}$ also elucidated the significance of eNOS as a seemingly promising strategy for targeting anti-androgen resistant prostate cancer. Arginine-releasing compounds such as carboxypeptidase-D increased NO production, which correlated with survival and progression of prostate cancer. ${ }^{53}$

\section{Cervical cancer}

Cervical cancer takes the second position as one of the most common female cancers recording $>200,000$ deaths per year. Its risk factors include chronic inflammation, long use of oral contraception, smoking, multiparity, and sexually transmitted diseases such as chlamydia, herpes. ${ }^{4}$ Cervical cells, such as squamous, glandular epithelial, and stromal cells, generate NO, which is a key signaling molecule shown to play an eminent role in various physiological processes (preparing the cervix for pregnancy, etc.). ${ }^{54}$ However, elevated levels of NO have been reported in cervical cancer patients, thereby indicating its mutagenic and carcinogenic potential in cervical cancer progression. NO plays a crucial role in the progression of cervical carcinogenesis through human papilloma virus (HPV). ${ }^{3}$ It was concluded that NO is a pragmatic cofactor that promotes HPV-induced cervical carcinogenesis. ${ }^{55}$ Moreover, susceptibility to HPV infection as observed through the cytological changes in the cervix correlates with an elevated expression of both eNOS and iNOS. ${ }^{27}$ Of these, iNOS, plays a prominent role in tumor progression, by promoting angiogenesis and thus regulating the level of VEGF. ${ }^{56}$ This explanation was corroborated by an iNOS knockdown experiment in HeLa cells that reduced their proliferation. ${ }^{57}$ High NO concentrations impair the migration of neutrophil migration, which express receptors necessary for extricating tumor cells in cervical neoplasia. ${ }^{57} \mathrm{NO}$ also encumbers the success rate of conventional treatment therapy. In a study by Chen et al., ${ }^{58}$ overexpression of iNOS along with COX-2 correlated with diminished survival rates of cervical cancer patients on 
radiotherapy regime.

\section{Breast cancer}

Breast cancer is the predominant cause of mortality among women worldwide. Tumorigenesis in the mammary gland has been reported to correlate with VNTR $4 \mathrm{a} / \mathrm{b}$ polymorphism that regulate eNOS expression. ${ }^{59} \mathrm{NO}$ can modulate tumor aggression in breast carcinoma through the inhibition of enzymes linked to DNA repair machinery. ${ }^{60,61}$ Moreover, iNOS inhibits DKK glycoprotein, which is crucial to regulating the Wnt/ $\beta$-catenin pathway. ${ }^{8}$ Abrogation of this pathway is activated in several tumors, including breast cancer. ${ }^{62} \mathrm{~A}$ diagnostic evaluation of inflammatory markers associated with breast cancer prognosis includes $\mathrm{NO}$ as well. ${ }^{63}$ Apoptosis of triple negative breast cancer cells have been attained through the modulation of iNOS activity. ${ }^{64}$ Knockdown of genes regulated by NO signaling pathway ameliorated breast tumor metastasis. ${ }^{65}$ Augsten et al. ${ }^{66}$ demonstrated an upregulation of NOS levels in CXCL14-expressing cancer-associated fibroblasts which triggers tumor growth and metastasis. The manifestation of chemo-resistance as well as metastasis in breast cancer cells are rendered through NO elevation, which therefore results in poor survival of patients. ${ }^{67}$ Importantly, NO induces tamoxifen-resistance in ER positive breast cancer. ${ }^{68}$

\section{Head and neck cancer}

One of the major causes of morbidity and mortality and the sixth most common cancer type is the oral squamous cell carcinoma. Its high occurrence is affiliated with the use of tobacco and tobacco-related products such as cigarettes. Tobacco components act as initiators of inflammation which consequently are responsible for the production of RNS. RNS hamper the antioxidant protective system and induce lipid peroxidation in tobacco users. ${ }^{4}$ Head and neck cancer (HNC) shows an increased level of NOS activity which is correlated with high levels of cGMP levels and vascularization in the tumor mass. Lymph node metastases are associated with microvessel density as well as high NOS activity, which is indicative of high metastatic nature. $^{69}$ Mutations in p53 have been correlated with overexpression of iNOS as well as oxidative stress. ${ }^{70}$ Patients with oral pre-cancer displayed high levels of $\mathrm{NO}_{2}$ and $\mathrm{NO}_{3}$ as well individuals with tobacco usage showed similar results. ${ }^{71}$ This is indicative of the injuries caused by the RNS in patients with pre-cancer as well healthy individual with tobacco usage. This aspect has a clinical relevance in acting as a biomarker of inflammation and can be utilized for the estimation of cancer risk. ${ }^{4}$ Ethanol stimulates NO generation and is important to the etiology of a few cancer including $\mathrm{HNC}^{4}$

\section{Lung cancer}

Lung cancer is one of the leading causes of mortality and morbidity at present. ${ }^{71}$ The primary cause for this devastating disease is tobacco smoke, which triggers chronic inflammation of the airway and activates leukocytes that produce ROS and NO at higher levels. An increased level of nitrite, nitrotyrosine, and NO are noted in lung cancer patients. ${ }^{72}$ Substantially higher levels of iNOS are observed in lung tissues of smokers in comparison to the non-smokers. ${ }^{4}$ It is observed that cigarette smoke has about $10^{14} \mathrm{ROS}$ and $700 \mathrm{ppm}$ NO in a single puff. ${ }^{73} \mathrm{~A}$ high level of NO is present in the exhaled air from the lung cancer patients in comparison to healthy controls. A significantly high level of nitrated proteins were found in the serum correlating to the presence of nitrosative and oxidative stress. ${ }^{73}$

It was also demonstrated that cells treated with NO over a long period of time increased the number of filopodia per cell and cell division cycle 42 protein was also found to be in higher concentration. This shows that long term exposure of cells to NO has a unique effect on migratory potential of the cells via caveolin-1-dependent mechanism. ${ }^{73}$ NO works towards carcinogenesis by nitrating proteins. Nitration of proteins takes place by the reaction of NO and its metabolites with ROS which lead to production of high caliber nitrating agents. One of the main chemical modifications occurring due to oxidative/nitrosative stress is the formation of 3-nitrotyrosine in proteins. NO at high levels deactivates $\mathrm{p} 53$ which consequently aids in the progression of cancer and it stands true in $90 \%$ of lung cancer cases, which are found to be $\mathrm{p} 53$ defective. ${ }^{4}$

\section{Gastric cancer}

Having witnessed abundant advances in the field of therapeutics, some diseases still remain as a global threat to life: one among them is gastric cancer. It is well established that the carcinogenesis of the gastric tissues is positively attributed to infection of Helicobacter pylori and excessive intake of salt ${ }^{4}$ whereas there has been a debate on whether alcohol consumption and tobacco smoking are associated with the neoplastic transformation. Interestingly, all the three isoforms of NOS (nNOS, iNOS, and eNOS) express in the gastric canal. High expression levels of iNOS and eNOS have been observed in human colorectal cancers. ${ }^{4}$ Tumor angiogenesis plays a vital role in progression of the cancerous cells and result in metastasis. Cell proliferation promotes by supplying blood vessels to the tumor 
by VEGF, which aids in the formation new blood vessels. The levels of VEGF correlate with the levels of NO. High serum VEGF levels were noted in gastric cancer patients in comparison to the healthy control group, which directly indicates that NO plays an important role in the progression of cancer by providing means of better blood supply and ways for cancer cells to establish new centers via metastasis. $^{74}$

\section{Brain tumors}

Many vital physiological activities, such as vasculature and neurotransmission, are influenced by NO. Many disorders of the central nervous system portray $\mathrm{NO}$ as an important mediator of neurotoxicity. nNOS expression is an indicator for differentiation of brain tumor and malignancy. Unexpected high NO levels are observed in central nervous system malignancies and this suggests that there is some correlation between NO production and pathophysiological processes of tumor progression. ${ }^{4}$

\section{CHEMOPREVENTION AND ITS ROLE FOR NITRIC OXIDE PRODUCTION}

Conventional chemotherapeutic drugs are a part of standard cancer treatment regime. While several drugs have displayed anti-inflammatory and pro-apoptotic activity via alleviation of NO signalling, ${ }^{75}$ patients administered with drugs, namely tamoxifen citrate, capecitabine, and epirubicin, have incurred cardiovascular and other cytotoxicity through the aggravation of NO signaling. ${ }^{76}$ Moreover, chronic inflammation, which is involved in the elevation of markers such as cytokines and NO, is associated with immunosuppression in cancer, thereby hindering the survival outcome of patients. ${ }^{77}$ Owing to these complexities, chemoprevention may be the new buzzword and hence there have been ongoing attempts to evaluate multidimensional involvement of chemopreventive agents through targeting various hallmarks of cancer (Fig. 4). ${ }^{78}$ Chemoprevention focuses on the identification of certain dietary agents that can, if not completely cure, alleviate cancer proliferation in the body. Certain dietary agents and phytochemicals with chemopreventive potential involve anti-inflammatory mechanisms that reduce NO levels and consequently help to inhibit the function of genes and markers involved in tumor progression, thereby abating the process of carcinogenesis. Many phytochemicals such as flavonoids showed to inhibit lipopolysaccharide-stimulated iNOS expression. ${ }^{79}$ Therefore, unravelling the potential of promising natural agents with chemopreventive capabilities may help to alleviate NO induced inflammation observed during carcinogenesis. $^{78,80}$

\section{REVERSAL OF CANCER HALLMARKS THROUGH CHEMOPREVENTION}

As mentioned above, the alluring effects of various chemopreventive agents in reinstating NO levels that control the successive stages of tumor progression has been recognized. ${ }^{81} \mathrm{~A}$ colossal amount of data indicated that chemopreventive agents with antioxidant and anti-carcinogenic potential, reduced NO-induced modulation of genes which influence cancer proliferation, metastasis, and angiogenesis. ${ }^{82}$ Hence, based on the molecular markers targeted at various stages of tumor progression, chemopreventive agents have been classified as non-steroidal anti-inflammatory drugs (NSAIDs). ${ }^{83}$

Some NSAIDs act as COX-2 inhibitors that play an antiinflammatory and anti-angiogenic role. ${ }^{83}$ COX-2 triggers the inflammatory process during NO-mediated tumor proliferation. COX-2 suppression has shown to simultaneously inhibit NO levels. Celecoxib, a COX-2 inhibitor, has been proven to be an effective chemopreventive agent against breast and colon cancer to alleviate angiogenesis and metastasis in combination treatment with anti-angiogenic agents. Curcumin, inhibits extracellular-signal regulated kinase (ERK) and consequently hinders translation of NF- $\mathrm{KB}$ and COX-2, ${ }^{82}$ both of which are involved in the regulation of $\mathrm{NO}^{82}$ Curcumin attenuates $\mathrm{NO}$ and COX-2 through a post transcriptional event, thereby aiding in colon cancer prevention through its anti-inflammatory efficacy. ${ }^{83}$ Another COX-2 inhibitor, resveratrol, suppressed inducible NO levels in SW480 human colon cancer cells by phosphorylating of inhibitor of $\mathrm{\kappa B}(\mathrm{I} \kappa \mathrm{B}){ }^{84}$ Soyasaponin, an another anti-inflamma-

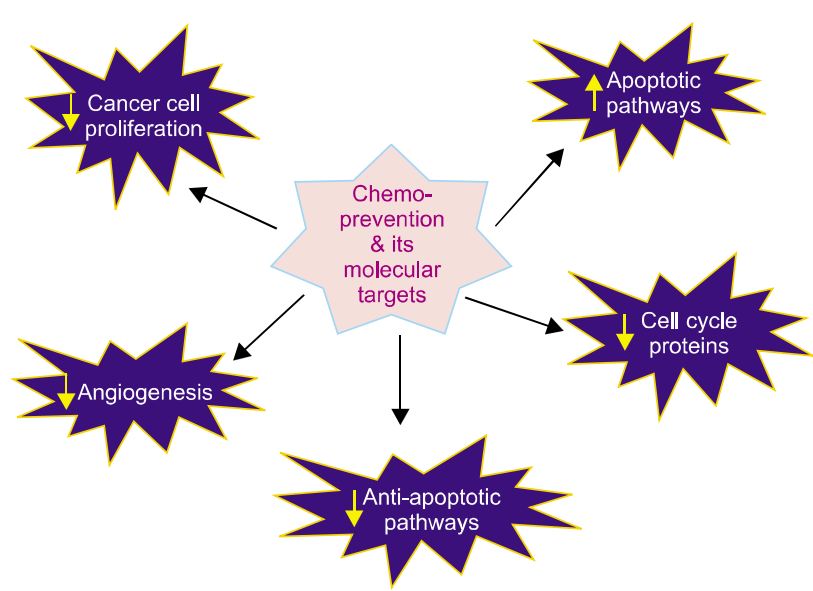

Figure 4. Molecular targets of chemo-preventive agents. 
tory agent, was also shown to reduce NO production, by reducing COX-2 and inducible NOS expression in prostate colon and breast cancers. ${ }^{85}$ Aspirin enhances the endogenous production of maspin, which inhibits invasion and metastasis in breast tumors, via the restoration of NO production. ${ }^{86}$ Aliphatic isothiocyanates, such as sulphorafane (SFN) abundant in cruciferous vegetables, were indicated in a study to down regulate the expression of iNOS and COX-2 through the thiol-dependent inhibition of DNA binding to NF-KB. ${ }^{87}$ Similar results were obtained and further suggested that a combination of SFN and curcumin may be more effective in synergistically downregulating the activity of inflammatory markers such as TNF, IL-1 and NO. ${ }^{88}$ Anti-estrogenic agents, such as genestein, also inactivated NF- $\mathrm{KB}$ via downregulation of Akt in numerous cell lines. ${ }^{89}$ Epigallocatechin gallate (EGCG) protects cellular damage, which is partly imparted through NO elevation, by blocking inflammatory kinases such as AKT and PI3K.

The efficacy of numerous chemopreventive agents in inhibiting angiogenesis have been investigated since long before. $^{84}$ To elucidate their anti-angiogenic mechanism, researchers sought to correlate NO with other pro-angiogenic factors such as VEGF in various experiments. ${ }^{88}$ VEGF exacerbates NO production during angiogenesis. ${ }^{86}$ Natural dietary VEGF inhibitors have therefore shown to control tumor angiogenesis. ${ }^{87}$ VEGF pathway-based therapy has been successful in curbing down angiogenesis by decreasing NO production. ${ }^{88}$ Flavolignans such as silibinin exerted their anti-angiogenic role by downregulating iNOS activity in lung cancer. ${ }^{80}$ Dietary alkaloids, such as harmine, inhibited the anomalous elevation of pro-angiogenic factors, especially $\mathrm{NO}$ and $\mathrm{VEGF}^{89}$ iNOS aggravates angiogenesis by the activation of PI3K-AKT-mTOR pathway in melanoma and several other cancers. This activation was reversed by treatment with magnolol, a hydroxylated biphenyl compound extracted from Magnolia officinalis. Magnolol was able to avert the angiogenic events induced by VEGF, such as the activation of Akt/eNOS pathway. However, since reduction in endothelial NO bioavailability has been associated with hypertension in patients with VEGF therapy, further research is required to prove its efficacy. Interestingly, reduction in endothelin-1 in patient samples with VEGF therapy was able to ameliorate the elevated blood pressure levels.

Certain dietary agents render themselves as anti-metastatic agents by targeting NO levels. NO has been implicated in the activation of c-Src (a non-receptor tyrosine kinase) which is involved in tumor progression and metastasis. ${ }^{90}$ Studies in breast cancer elucidated its mechanism by showing that c-Src activation by $\beta$-estradiol, depended on the production of $\mathrm{NO}^{91}$ Furthermore, the NO-mediated c-Src activation suppressed E-Cadherin expression. ${ }^{92}$ Consequently, loss of E-cadherin expression is a hallmark feature in cancer that instigates the disruption of cell-cell adhesion and hence tumor cell invasion. ${ }^{90}$ Modulation of E-cadherin in conjunction with overexpression of TGF- $\beta 1$ has especially shown to play a critical role in carcinogenesis of the urinary bladder. ${ }^{90}$ Among the many available chemopreventive agents (Table 1), EGCG's inhibitory role in the invasion of A375 cells was attributed, to the upregulation of E-cadherin in a concentration and time dependant manner. ${ }^{8} \mathrm{Du}$ et al. $^{62}$ suggested the anti-metastatic effect of EGCG by the enhanced expression of p27 and E-cadherin in human glioma cells. Another study demonstrated that the suppression of cell migration by EGCG in bladder cancer was through the inactivation of $\mathrm{N}$-cadherin, which was in turn due to inactivation of Akt signalling. ${ }^{21}$ Zhang et al. elucidated the eminent role of EGCG in inhibiting angiogenesis, via the

Table 1. Chemo-preventive agents and their molecular targets

\begin{tabular}{|c|c|c|c|}
\hline Chemo-preventive agents & Source & Molecular target & Reference No. \\
\hline Curcumin & Turmeric & $\begin{array}{l}\text { Inhibition of IKB } \alpha, E R K 1 / 2 \\
\text { downregulation of } N F-\kappa B\end{array}$ & 93,94 \\
\hline Gingerol & Ginger & Inhibition of cell development factor & 93,94 \\
\hline Epigallocatechin gallate & Green tea & Inhibition of AP1, VEGF, STAT3, and NF- $\mathrm{KB}$ & 93,94 \\
\hline Capsaicin & Pepper & Induction of apoptosis and inhibition NF-KB expression & 93,94 \\
\hline Genistein & Soybeans & Suppression of NF-KB and AKT & 93,94 \\
\hline Resveratrol & Red grapes & $\begin{array}{l}\text { Inhibition of PKC and AP1 transformation } \\
\text { Reduced NF- } \mathrm{KB} \text { expression }\end{array}$ & 93,94 \\
\hline Quercitin & Caper & Caspase-dependent apoptosis & 93,94 \\
\hline Sulforaphane & Broccoli & Inactivation of NF-KB binding with DNA. & 93,94 \\
\hline Lycopene & Tomato & Upregulation of antioxidant response element & 93,94 \\
\hline Eugenol & Cloves & Downregulation of Bcl-2, COX-2, and IL-1 $\beta$. & 93. 94 \\
\hline
\end{tabular}

ERK, extracellular-signal regulated kinase; PKC, protein tyrosine kinase; AP1, activator protein-1; IL-1 $\beta$, interleukin $1 \beta$. 
downregulation of vascular endothelial-cadherin and $\mathrm{Akt.}^{25}$ Other agents such as dithiolethione modified valproate, sulindac and diclofenac, were collectively shown to enhance E-cadherin expression in non-small cell lung cancer. ${ }^{86}$

Like E-cadherin, MMP is also involved in the loss of cellular adhesion, thereby enabling the cells to metastasize. Previous studies have shown a reciprocal relationship between NOS and MMP levels, which collectively exacerbate tumor invasion and metastasis. Knockdown experiments by Zhang et al. ${ }^{25}$ confirmed that decreased production of L-arginine-induced NO, subsequently decreased the expression of MMP-1 levels in melanoma cells. The activation of transcription factors, namely ERK-1/2 and AP-1, elucidated the notorious role of NO towards triggering cancer metastasis via MMP-9. ${ }^{89}$ Furthermore, Patruno et al. ${ }^{92}$ provided further insight into the mechanism of MMP upregulation. Based on their results on human acute monocytic leukemia cells, they indicated an aberration in iNOS through environmental influence. This affected the expression of tissue inhibitors of MMPs involved in the regulation of MMPs. Ipobscurine, an indole alkaloid, suppressed the activation of genes involved in metastasis and tumor proliferation, namely MMPs, caspase-3, p53, Bax, and transcription factors such as NF-KB. ${ }^{91-94}$

Several chemopreventive agents, including terpenes, sulphides, phenols, organic acids, and other macromolecules, modulate carcinogen detoxification enzymes. For example, the major mechanism by which SFN and other organosulfur compounds exert their anti-carcinogenic potential is by upregulating the transcription of glutathione S-transferase $\mathrm{P}$ (GSTP), a phase II detoxification enzyme, via the activation of c-jun and Nrf2 binding to enhancer element enhancer I of GSTP. ${ }^{85}$ Several studies suggest the upregulation of GSTP1 in various tumors. ${ }^{86}$ Downregulation of GSTP1 resulted in increased susceptibility to gastric, colorectal, and lung cancer progression. ${ }^{92}$ Apart from its role in detoxification, GST enzymes are also involved in the regulation of NO pathways. ${ }^{8}$ Kenneth and his co-workers used a GST-null mice to demonstrate the significant elevation in the level of inflammatory genes, including iNOS in colon cancer. ${ }^{87}$ GST- $\pi$ is over-expressed in oral cancer in conjunction with NO obtained from cigarette smoke. ${ }^{88}$ Various chemopreventive agents, such as green tea extracts, broccoli sprout extracts, EGCG, phenethyl isothiocyanate, and benzyl isothiocyanate, were also able to augment phase II enzyme activity (GSTP1), in lung cancer. ${ }^{7}$ SFN activated Nrf, involved in the induction of phase 2 detoxification enzymes which predominantly downregulates during oncogenesis. ${ }^{88}$

\section{CONCLUSION}

The chemopreventive agents induce NO production and thus facilitate apoptosis. Thus, chemoprevention shows a potential to be used for cancer therapeutics in the near future and one of its main target would be NO.

\section{ACKNOWLEDGMENTS}

The authors acknowledge Zayed University Research Incentive Fund (RIF) (activity code: R14020) for the financial support. The authors are also grateful to Ms. Madhumitha Kedhari Sundaram and Payal Goala for their valuable suggestions in preparing this review article.

\section{CONFLICTS OF INTEREST}

No potential conflicts of interest were disclosed.

\section{REFERENCES}

1. Vannini F, Kashfi K, Nath N. The dual role of iNOS in cancer. Redox Bio 2015;6:334-43.

2. Fukumura D, Kashiwagi S, Jain RK. The role of nitric oxide in tumour progression. Nat Rev Cancer 2006;6:521-34.

3. Burke AJ, Sullivan FJ, Giles FJ, Glynn SA. The yin and yang of nitric oxide in cancer progression. Carcinogenesis 2013;34:503-12.

4. Choudhari SK, Chaudhary M, Bagde S, Gadbail AR, Joshi V. Nitric oxide and cancer: a review. World J Surg Oncol 2013;11:118.

5. Lee SY, Rim Y, McPherson DD, Huang SL, Kim H. A novel liposomal nanomedicine for nitric oxide delivery and breast cancer treatment. Biomed Mater Eng 2014:24:61-7.

6. Ohnishi S, Ma N, Thanan R, Pinlaor S, Hammam O, Murata M, et al. DNA damage in inflammation-related carcinogenesis and cancer stem cells. Oxid Med Cell Longev 2013. doi: 10.1155/2013/ 387014.

7. Wu Y, Hu X, Song L, Zhu J, Yu R. The inhibitory effect of a novel polypeptide fraction from Arca subcrenata on cancer-related inflammation in human cervical cancer HeLa cells. ScientificWorldJournal 2014. doi: 10.1155/2014/768938.

8. Wink DA, Ridnour LA, Hussain SP, Harris CC. The reemergence of nitric oxide and cancer. Nitric Oxide 2008;19:65-7.

9. Harada K, Supriatno, Kawaguchi S, Tomitaro O, Yoshida H, Sato $\mathrm{M}$. Overexpression of iNOS gene suppresses the tumorigenicity and metastasis of oral cancer cells. In Vivo 2004;18:449-55.

10. Hickok JR, Thomas DD. Nitric oxide and cancer therapy: the emperor has NO clothes. Curr Pharm Des 2010;16:381-91.

11. Lahdenranta J, Hagendoorn J, Padera TP, Hoshida T, Nelson G, Kashiwagi S, et al. Endothelial nitric oxide synthase mediates lymphangiogenesis and lymphatic metastasis. Cancer Res 2009; 69:2801-8.

12. Qiu Y, Li WH, Zhang HQ, Liu Y, Tian XX, Fang WG. P2X7 mediates 
ATP-driven invasiveness in prostate cancer cells. PLoS One 2014:9:e114371.

13. Li N, Deng W, Ma J, Wei B, Guo K, Shen W, et al. Prognostic evaluation of Nanog, Oct4, Sox2, PCNA, Ki67 and E-cadherin expression in gastric cancer. Med Oncol 2015;32:433.

14. Huang JW, Guan BZ, Yin LH, Liu FN, Hu B, Zheng QY, et al. Effects of estrogen-related receptor alpha (ERR $\alpha$ ) on proliferation and metastasis of human lung cancer A549 cells. J Huazhong Univ Sci Technolog Med Sci 2014;34:875-81.

15. Cardenas H, Vieth E, Lee J, Segar M, Liu Y, Nephew KP, et al. TGF- $\beta$ induces global changes in DNA methylation during the epithelial-to-mesenchymal transition in ovarian cancer cells. Epigenetics 2014:9:1461-72.

16. Hama S, Takeichi O, Fujisaki K, Tanabe N, Maeno M, Ochiai K. Nitric oxide attenuates vascular endothelial cadherin-mediated vascular integrity in human chronic inflammation. Clin Exp Immunol 2008;154:384-90.

17. Ridnour LA, Windhausen AN, Isenberg JS, Yeung N, Thomas DD, Vitek MP, et al. Nitric oxide regulates matrix metalloproteinase-9 activity by guanylyl-cyclase-dependent and -independent pathways. Proc Natl Acad Sci U S A 2007;104:16898-903.

18. Weiss JM, Ridnour LA, Back T, Hussain SP, He P, Maciag AE, et al. Macrophage-dependent nitric oxide expression regulates tumor cell detachment and metastasis after IL-2/anti-CD40 immunotherapy. J Exp Med 2010;207:2455-67.

19. Leon L, Jeannin JF, Bettaieb A. Post-translational modifications induced by nitric oxide (NO): implication in cancer cells apoptosis. Nitric Oxide 2008;19:77-83.

20. Aqil M, Elseth KM, Vesper BJ, Deliu Z, Aydogan B, Xue J, et al. Part I-mechanism of adaptation: high nitric oxide adapted A549 cells show enhanced DNA damage response and activation of antiapoptotic pathways. Tumour Biol 2014;35:2403-15.

21. Huang K, Li LA, Meng YG, You YQ, Fu XY, Song L. Arctigenin promotes apoptosis in ovarian cancer cells via the iNOS/NO/ STAT3/survivin signalling. Basic Clin Pharmacol Toxicol 2014; 115:507-11.

22. Huerta-Yepez S, Baritaki S, Baay-Guzman G, Hernandez-Luna MA, Hernandez-Cueto A, Vega MI, et al. Contribution of either YY1 or BclXL-induced inhibition by the NO-donor DETANONOate in the reversal of drug resistance, both in vitro and in vivo. YY1 and BclXL are overexpressed in prostate cancer. Nitric Oxide 2013; 29:17-24.

23. Pervin S, Singh R, Hernandez E, Wu G, Chaudhuri G. Nitric oxide in physiologic concentrations targets the translational machinery to increase the proliferation of human breast cancer cells: involvement of mammalian target of rapamycin/eIF4E pathway. Cancer Res 2007:67:289-99.

24. Yamaguchi M. The anti-apoptotic effect of regucalcin is mediated through multisignaling pathways. Apoptosis 2013;18:1145-53.

25. Zhang HX, Deng C, Liu OS, Liu XL, Wu F, Wang JJ, et al. Inducible nitric oxide inhibitor enhances the anti-tumor effect of cisplatin on CNE-2 cells by inducing cell apoptosis. Eur Rev Med Pharmacol Sci 2014; 18:2789-97.

26. Takaoka K, Hidaka S, Hashitani S, Segawa E, Yamamura M, Tanaka N, et al. Effect of a nitric oxide synthase inhibitor and a CXC chemokine receptor-4 antagonist on tumor growth and metastasis in a xenotransplanted mouse model of adenoid cystic carcinoma of the oral floor. Int J Oncol 2013:43:737-45.

27. Ying L, Hofseth LJ. An emerging role for endothelial nitric oxide synthase in chronic inflammation and cancer. Cancer Res 2007; 67:1407-10.

28. MacLauchlan S, Yu J, Parrish M, Asoulin TA, Schleicher M, Krady $\mathrm{MM}$, et al. Endothelial nitric oxide synthase controls the expression of the angiogenesis inhibitor thrombospondin 2. Proc Natl Acad Sci U S A 2011;108:E1137-45.

29. Robinson ES, Khankin EV, Choueiri TK, Dhawan MS, Rogers MJ, Karumanchi SA, et al. Suppression of the nitric oxide pathway in metastatic renal cell carcinoma patients receiving vascular endothelial growth factor-signaling inhibitors. Hypertension 2010;56: 1131-6.

30. Ambs S, Merriam WG, Bennett WP, Felley-Bosco E, Ogunfusika MO, Oser SM, et al. Frequent nitric oxide synthase-2 expression in human colon adenomas: implication for tumor angiogenesis and colon cancer progression. Cancer Res 1998:58:334-41.

31. Shang ZJ, Li JR. Expression of endothelial nitric oxide synthase and vascular endothelial growth factor in oral squamous cell carcinoma: its correlation with angiogenesis and disease progression. J Oral Pathol Med 2005;34:134-9.

32. Shen BQ, Lee DY, Zioncheck TF. Vascular endothelial growth factor governs endothelial nitric-oxide synthase expression via a $\mathrm{KDR} / \mathrm{Flk}$-1 receptor and a protein kinase $\mathrm{C}$ signaling pathway. J Biol Chem 1999:274:33057-63.

33. Rathnasamy G, Sivakumar V, Rangarajan P, Foulds WS, Ling EA, Kaur C. NF-KB-mediated nitric oxide production and activation of caspase-3 cause retinal ganglion cell death in the hypoxic neonatal retina. Invest Ophthalmol Vis Sci 2014:55:5878-89.

34. Okada H, Tsuzuki T, Shindoh H, Nishigaki A, Yasuda K, Kanzaki $\mathrm{H}$. Regulation of decidualization and angiogenesis in the human endometrium: mini review. J Obstet Gynaecol Res 2014:40:1180-7.

35. Katanasaka Y, Kodera Y, Kitamura Y, Morimoto T, Tamura T, Koizumi F. Epidermal growth factor receptor variant type III markedly accelerates angiogenesis and tumor growth via inducing c-myc mediated angiopoietin-like 4 expression in malignant glioma. Mol Cancer 2013;12:31.

36. Lo HW, Hsu SC, Ali-Seyed M, Gunduz M, Xia W, Wei Y, et al. Nuclear interaction of EGFR and STAT3 in the activation of the iNOS/NO pathway. Cancer Cell 2005;7:575-89.

37. Kao YC, Jiang SJ, Pan WA, Wang KC, Chen PK, Wei HJ, et al. The epidermal growth factor-like domain of $\mathrm{CD} 93$ is a potent angiogenic factor. PLoS One 2012;7:e51647.

38. Gallo O, Franchi A, Magnelli L, Sardi I, Vannacci A, Boddi V, et al. Cyclooxygenase-2 pathway correlates with VEGF expression in head and neck cancer. Implications for tumor angiogenesis and metastasis. Neoplasia 2001;3:53-61.

39. Sano H, Kawahito Y, Wilder RL, Hashiramoto A, Mukai S, Asai K, et al. Expression of cyclooxygenase-1 and -2 in human colorectal cancer. Cancer Res 1995:55:3785-9.

40. Guo L, Li SY, Ji FY, Zhao YF, Zhong Y, Lv XJ, et al. Role of Angptl4 in vascular permeability and inflammation. Inflamm Res 2014; 63:13-22.

41. Chong HC, Chan JS, Goh CQ, Gounko NV, Luo B, Wang X, et al. Angiopoietin-like 4 stimulates STAT3-mediated iNOS expression and enhances angiogenesis to accelerate wound healing in diabetic mice. Mol Ther 2014;22:1593-604.

42. Ziche M, Morbidelli L. Molecular regulation of tumour angiogenesis by nitric oxide. Eur Cytokine Netw 2009;20:164-70.

43. Cinel L, Polat A, Aydin O, Düşmez D, Eğilmez R. Bcl-2, iNOS, p53 and PCNA expression in normal, disordered proliferative, hyper- 
plastic and malignant endometrium. Pathol Int 2002;52:384-9.

44. Ozel E, Peştereli HE, Simşek T, Erdoğan G, Karaveli FS. Expression of cyclooxygenase-2 and inducible nitric oxide synthase in ovarian surface epithelial carcinomas: is there any correlation with angiogenesis or clinicopathologic parameters? Int J Gynecol Cancer 2006; 16:549-55.

45. Oztürk E, Dikensoy E, Balat O, Uğur MG, Balcı SO, Aydın A, et al. Association of endothelial nitric oxide synthase gene polymorphisms with endometrial carcinoma: a preliminary study. J Turk Ger Gynecol Assoc 2011:12:229-33.

46. Safarinejad MR, Safarinejad S, Shafiei N, Safarinejad S. Effects of the T-786C, G894T, and Intron 4 VNTR (4a/b) polymorphisms of the endothelial nitric oxide synthase gene on the risk of prostate cancer. Urol Oncol 2013;31:1132-40.

47. Zhao C, Yan W, Zu X, Chen M, Liu L, Zhao S, et al. Association between endothelial nitric oxide synthase $894 \mathrm{G}>\mathrm{T}$ polymorphism and prostate cancer risk: a meta-analysis of literature studies. Tumour Biol 2014:35:11727-33.

48. Nikolić ZZ, Pavićević DLj, Romac SP, Brajušković GN. Genetic variants within endothelial nitric oxide synthase gene and prostate cancer: a meta-analysis. Clin Transl Sci 2015;8:23-31.

49. Wu JH, Yang K, Ma HS, Xu Y. Association of endothelia nitric oxide synthase gene rs1799983 polymorphism with susceptibility to prostate cancer: a meta-analysis. Tumour Biol 2014;35:7057-62.

50. Cai C, Hsieh CL, Gao S, Kannan A, Bhansali M, Govardhan K, et al. Soluble guanylyl cyclase $\alpha 1$ and p53 cytoplasmic sequestration and downregulation in prostate cancer. Mol Endocrinol 2012;26: 292-307.

51. Lai CS, Li S, Miyauchi Y, Suzawa M, Ho CT, Pan MH. Potent anti-cancer effects of citrus peel flavonoids in human prostate xenograft tumors. Food Funct 2013:4:944-9.

52. Yu S, Jia L, Zhang Y, Wu D, Xu Z, Ng CF, et al. Increased expression of activated endothelial nitric oxide synthase contributes to antiandrogen resistance in prostate cancer cells by suppressing androgen receptor transactivation. Cancer Lett 2013; 328:83-94

53. Thomas LN, Morehouse TJ, Too CK. Testosterone and prolactin increase carboxypeptidase-D and nitric oxide levels to promote survival of prostate cancer cells. Prostate 2012;72:450-60.

54. Agarwal A, Gupta S, Sharma RK. Role of oxidative stress in female reproduction. Reprod Biol Endocrinol 2005;3:28.

55. Wei L, Gravitt PE, Song H, Maldonado AM, Ozbun MA. Nitric oxide induces early viral transcription coincident with increased DNA damage and mutation rates in human papillomavirus-infected cells. Cancer Res 2009;69:4878-84.

56. Hiraku Y, Tabata T, Ma N, Murata M, Ding X, Kawanishi S. Nitrative and oxidative DNA damage in cervical intraepithelial neoplasia associated with human papilloma virus infection. Cancer Sci 2007;98:964-72.

57. Dong J, Cheng M, Sun H. Function of inducible nitric oxide synthase in the regulation of cervical cancer cell proliferation and the expression of vascular endothelial growth factor. Mol Med Rep 2014;9:583-9.

58. Chen HH, Su WC, Chou CY, Guo HR, Ho SY, Que J, et al. Increased expression of nitric oxide synthase and cyclooxygenase-2 is associated with poor survival in cervical cancer treated with radiotherapy. Int J Radiat Oncol Biol Phys 2005;63:1093-100.

59. Ramírez-Patiño R, Figuera LE, Puebla-Pérez AM, Delgado-Saucedo JI, Legazpí-Macias MM, Mariaud-Schmidt RP, et al. Intron 4 VNTR (4a/b) polymorphism of the endothelial nitric oxide synthase gene is associated with breast cancer in Mexican women. J Korean Med Sci 2013;28:1587-94.

60. Chang CF, Diers AR, Hogg N. Cancer cell metabolism and the modulating effects of nitric oxide. Free Radic Biol Med 2015;79: 324-36.

61. Rashad YA, Elkhodary TR, El-Gayar AM, Eissa LA. Evaluation of serum levels of HER2, MMP-9, nitric oxide, and total antioxidant capacity in Egyptian breast cancer patients: correlation with clinico-pathological parameters. Sci Pharm 2013;82:129-45.

62. Du Q, Zhang X, Cardinal J, Cao Z, Guo Z, Shao L, et al. Wnt/beta-catenin signaling regulates cytokine-induced human inducible nitric oxide synthase expression by inhibiting nuclear factorkappaB activation in cancer cells. Cancer Res 2009;69:3764-71.

63. Baskic D, Popovic S, Bankovic D, Arsovic A, Vukovic V, Zelen I, et al. Evaluation of inflammatory biomarkers as helping diagnostic tool in patients with breast cancer. Cancer Biomark 2014;14: 401-8.

64. Kanugula AK, Gollavilli PN, Vasamsetti SB, Karnewar S, Gopoju R, Ummanni $R$, et al. Statin-induced inhibition of breast cancer proliferation and invasion involves attenuation of iron transport: intermediacy of nitric oxide and antioxidant defence mechanisms. FEBS J 2014:281:3719-38.

65. Dave B, Granados-Principal S, Zhu R, Benz S, Rabizadeh S, Soon-Shiong P, et al. Targeting RPL39 and MLF2 reduces tumor initiation and metastasis in breast cancer by inhibiting nitric oxide synthase signaling. Proc Natl Acad Sci U S A 2014;111: 8838-43.

66. Augsten M, Sjöberg E, Frings O, Vorrink SU, Frijhoff J, Olsson E, et al. Cancer-associated fibroblasts expressing CXCL14 rely upon NOS1-derived nitric oxide signaling for their tumor-supporting properties. Cancer Res 2014:74:2999-3010.

67. Heinecke JL, Ridnour LA, Cheng RY, Switzer CH, Lizardo MM, Khanna C, et al. Tumor microenvironment-based feed-forward regulation of NOS2 in breast cancer progression. Proc Natl Acad Sci U S A 2014:111:6323-8.

68. Duan L, Danzer B, Levenson VV, Maki CG. Critical roles for nitric oxide and ERK in the completion of prosurvival autophagy in 4OHTAM-treated estrogen receptor-positive breast cancer cells. Cancer Lett 2014:353:290-300.

69. Gallo O, Masini E, Morbidelli L, Franchi A, Fini-Storchi I, Vergari WA, et al. Role of nitric oxide in angiogenesis and tumor progression in head and neck cancer. J Natl Cancer Inst 1998;90: 587-96.

70. Segawa Y, Oda Y, Yamamoto H, Uryu H, Shiratsuchi H, Hirakawa $\mathrm{N}$, et al. Overexpression of inducible nitric oxide synthase and accumulation of 8-OHdG in nasopharyngeal carcinoma. Histopathology 2008;52:213-23.

71. Masri F. Role of nitric oxide and its metabolites as potential markers in lung cancer. Ann Thorac Med 2010;5:123-7.

72. Puhakka A, Kinnula V, Näpänkangas U, Säily $M$, Koistinen $P$, Pääkkö $P$, et al. High expression of nitric oxide synthases is a favorable prognostic sign in non-small cell lung carcinoma. APMIS 2003;111:1137-46.

73. Sanuphan A, Chunhacha P, Pongrakhananon V, Chanvorachote P. Long-term nitric oxide exposure enhances lung cancer cell migration. Biomed Res Int 2013. doi: 10.1155/2013/186972.

74. Eroğlu A, Demirci S, Ayyildiz A, Kocaoğlu H, Akbulut H, Akgül H, et al. Serum concentrations of vascular endothelial growth factor 
and nitrite as an estimate of in vivo nitric oxide in patients with gastric cancer. Br J Cancer 1999;80:1630-4.

75. Takahashi M, Ota A, Karnan S, Hossain E, Konishi Y, Damdindorj $\mathrm{L}$, et al. Arsenic trioxide prevents nitric oxide production in lipopolysaccharide -stimulated RAW 264.7 by inhibiting a TRIF-dependent pathway. Cancer Sci 2013;104:165-70.

76. Gajalakshmi P, Priya MK, Pradeep T, Behera J, Muthumani K, Madhuwanti S, et al. Breast cancer drugs dampen vascular functions by interfering with nitric oxide signaling in endothelium. Toxicol Appl Pharmacol 2013;269:121-31.

77. Garcia AJ, Ruscetti M, Arenzana TL, Tran LM, Bianci-Frias D, Sybert E, et al. Pten null prostate epithelium promotes localized myeloid-derived suppressor cell expansion and immune suppression during tumor initiation and progression. Mol Cell Biol 2014:34:2017-28.

78. Panaro MA, Carofiglio V, Acquafredda A, Cavallo P, Cianciulli A. Anti-inflammatory effects of resveratrol occur via inhibition of lipopolysaccharide-induced NF- $\mathrm{KB}$ activation in Caco-2 and SW480 human colon cancer cells. Br J Nutr 2012;108:1623-32.

79. Tsuji PA, Stephenson KK, Wade KL, Liu H, Fahey JW. Structure-activity analysis of flavonoids: direct and indirect antioxidant, and antiinflammatory potencies and toxicities. Nutr Cancer 2013;65: 1014-25.

80. Ramasamy K, Dwyer-Nield LD, Serkova NJ, Kendra M, Tyagi A, Raina K, et al. NIH Public Access. 2012;17:753-61.

81. Sengupta A, Ghosh S, Bhattacharjee S. Dietary cardamom inhibits the formation of azoxymethane-induced aberrant crypt foci in mice and reduces COX-2 and iNOS expression in the colon. Asian Pac J Cancer Prev 2005;6:118-22.

82. Nasr M, Selima E, Hamed O, Kazem A. Targeting different angiogenic pathways with combination of curcumin, leflunomide and perindopril inhibits diethylnitrosamine-induced hepatocellular carcinoma in mice. Eur J Pharmacol 2014;723:267-75.

83. Keller JJ, Giardiello FM. Chemoprevention strategies using NSAIDs and COX-2 inhibitors. Cancer Biol Ther 2003;2:S140-9.

84. Masso-Welch PA, Zangani D, Ip C, Vaughan MM, Shoemaker S, Ramirez RA, et al. Inhibition of angiogenesis by the cancer chemopreventive agent conjugated linoleic acid. Cancer Res 2002;62: 4383-9.
85. Lankhorst S, Kappers MH, van Esch JH, Danser AH, van den Meiracker AH. Hypertension during vascular endothelial growth factor inhibition: focus on nitric oxide, endothelin-1, and oxidative stress. Antioxid Redox Signal 2014;20:135-45.

86. Thanigaimani S, Kichenadasse G, Mangoni AA. The emerging role of vascular endothelial growth factor (VEGF) in vascular homeostasis: lessons from recent trials with anti-VEGF drugs. Curr Vasc Pharmacol 2011;9:358-80.

87. Fernandez AP, Serrano J, Amorim MA, Pozo-Rodrigalvarez A, Martinez-Murillo R. Adrenomedullin and nitric oxide: implications for the etiology and treatment of primary brain tumors. CNS Neurol Disord Drug Targets 2011;10:820-33.

88. Kruzliak P, Novák J, Novák M. Vascular endothelial growth factor inhibitor-induced hypertension: from pathophysiology to prevention and treatment based on long-acting nitric oxide donors. Am J Hypertens 2014:27:3-13.

89. Hamsa TP, Kuttan G. Harmine inhibits tumour specific neo-vessel formation by regulating VEGF, MMP, TIMP and pro-inflammatory mediators both in vivo and in vitro. Eur J Pharmacol 2010;649: 64-73.

90. Kim KM, Kim NS, Kim J, Park JS, Yi JM, Lee J, et al. Magnolol suppresses vascular endothelial growth factor-induced angiogenesis by inhibiting Ras-dependent mitogen-activated protein kinase and phosphatidylinositol 3-kinase/Akt signaling pathways. Nutr Cancer 2013;65:1245-53.

91. Lankhorst S, Kappers MH, van Esch JH, Danser AH, van den Meiracker AH. Mechanism of hypertension and proteinuria during angiogenesis inhibition: evolving role of endothelin-1. J Hypertens 2013;31:444-54.

92. Patruno A, Pesce M, Marrone A, Speranza L, Grilli A, De Lutiis MA, et al. Activity of matrix metallo proteinases (MMPs) and the tissue inhibitor of MMP (TIMP)-1 in electromagnetic field-exposed THP-1 cells. J Cell Physiol 2012;227:2767-74.

93. Russo M, Spagnuolo C, Tedesco I, Russo GL. Phytochemicals in cancer prevention and therapy: truth or dare? Toxins (Basel) 2010:2:517-51.

94. Ugbogu AE, Akubugwo EI, Iweala EJJ, Uhegbu FO, Chinyere GC, Obasi NA. Role of phytochemicals in chemoprevention of cancer: a review. Int J Pharm Chem Sci 2013;2:566-75. 